\title{
Entrevista com Miriam Aparecida Alves
}

\author{
Joelma Santana Siqueira (Universidade Federal de Viçosa) \\ Vivaldo Andrade dos Santos (Georgetown University)
}

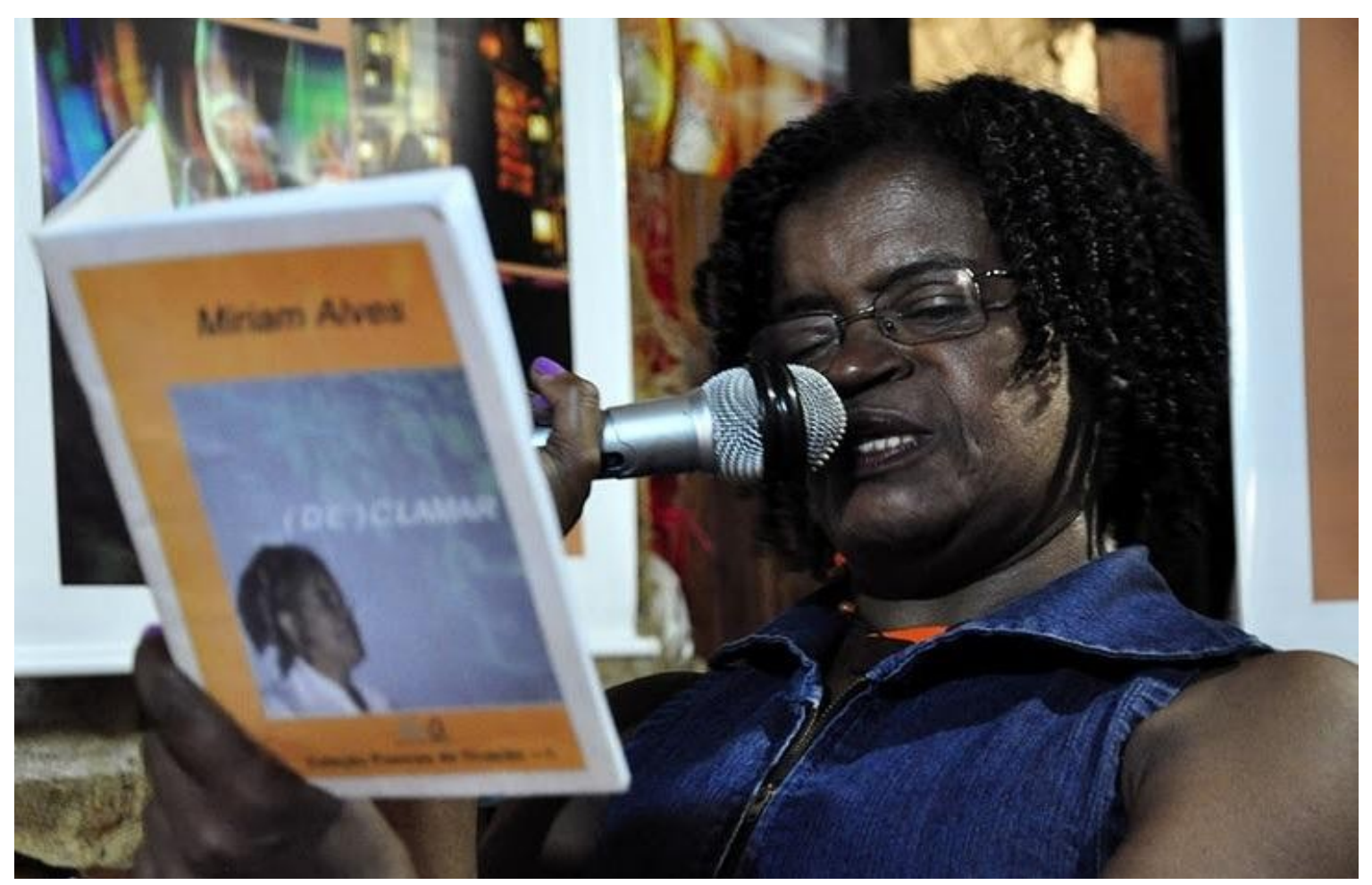

Fonte: Recanto do Poeta. Disponível em: https://recantodopoeta.com/miriam-alves/.

Miriam Aparecida Alves nasceu em São Paulo em 1952. É assistente social, professora, escritora e poeta. Integrou o Quilombhoje Literatura de 1980 a 1989. Publicou as seguintes obras: Momentos de Busca, poemas, em 1983; Estrelas nos Dedos, poemas, em 1985; Terramara, peça teatral, em 1988, em co-autoria com Arnaldo Xavier e Cuti (Luiz Silva); Brasilafro autorrevelado, ensaios, em 2010; Mulher Mat(r)iz, em 2011, contos; Bará na trilha do vento, em 2015, romance; Maréia, 2019, romance. Seus poemas e contos fazem parte da série Cadernos Negros (Vol. 5, 1982 até Vol. 40 2017). Tem diversos contos e poemas em antologias nacionais, como O Negro em versos: antologia da poesia negra brasileira, 2005; Olhos de Azeviche: dez escritoras negras que estão renovando a literatura brasileira, 2017; A Escritora Afro-Brasileira, ativismo e arte literária,2016; e internacionais, como Black notebooks: contemporary afro-Brazilian literary movement, nos Estados Unidos; Moving

Gláuks: Revista de Letras e Artes - jul/dez 2020 - v. 20, n. 2 
beyond boundaries. International Dimension of Black women's writing, 1995, na Inglaterra; Schwarze poesie: Poesia Negra, 1988; e Schwarze prosa: Prosa Negra, 1992, na Alemanha. Co-organizou duas antologias bilíngues: Finally us: Contemporary Black Brazilian Women Writers, 1995, e Women righting - Afro-Brazilian Women's Short Fiction, 2005. Como escritora visitante, esteve na Universidade do Novo México, no segundo semestre de 2007, e na Escola de Português de Middlebury College, em 2010, nos Estados Unidos da América, quando ministrou os cursos de Literatura e Cultura Afro-brasileira.

\section{Prezada Miriam Alves, somos muito gratos a você por nos conceder essa entrevista} para o presente dossiê da Gláuks dedicado ao tema "A literatura brasileira no exterior". Para iniciarmos, pedimos que nos fale sobre como é escrever e publicar literatura no Brasil.

Como escritora negra, é um exercício de resistência e de persistência, porque existem várias barreiras a serem quebradas. A primeira é passar pelo descrédito de que nós, negros e negras, podemos escrever ficcionalmente, podemos fazer literatura e publicar. Superada a primeira começamos a enfrentar a outra barreira, que é ir atrás de editoras para fazer esse material chegar ao público leitor. Aí complica, porque, normalmente, aquele primeiro descrédito de que você escreve mesmo, de que negro escreve, passa a ser para publicar. $\mathrm{O}$ resultado do nosso material escrito nunca é avaliado como tendo qualidade estética, uma qualidade literária para, como eles falam, “o projeto editorial desta editora”. Para quebrar essas barreiras, o que fizemos? Nós inventamos a nossa própria forma de publicar, sendo Cadernos Negros um dos meus maiores exemplos, que há quarenta e dois anos está aqui no Brasil publicando uma literatura negra brasileira. Cadernos Negros, surge em 1978 dentro de toda efervescência do Movimento Negro Unificado (MNU). Começa a aglutinar escritores e escritoras e inicia-se o que eu chamo de Movimento de Literatura Negra Brasileira, denominação que muitos dos pesquisadores e professores acadêmicos ainda têm uma resistência muito grande de adotar. A partir de 1978, abre-se um caminho que agencia não só os escritores antigos, novos escritores, como também leitores. Uma ação que tem quarenta e

Gláuks: Revista de Letras e Artes - jul/dez 2020 - v. 20, n. 2 
dois anos com a publicação de um livro por ano. Respondendo a sua pergunta, tentando ser sucinta: realmente, publicar literatura no Brasil é complicado. Publicar literatura negra no Brasil é muito complicado.

\section{Você considera que há diferenças que mereçam ser destacadas entre a recepção que sua obra tem no Brasil e a que tem no exterior?}

Completando o meu relato sobre dificuldades, tem a questão da visibilidade na mídia hegemônica. Assim sendo, o meu reconhecimento como escritora, veio primeiro do exterior, principalmente nos Estados Unidos, muito antes que aqui no Brasil. Eu fui convidada para ir para várias universidades nos Estados Unidos, a primeira cidade foi Miami, participei em 1996 da International Conference of Caribbean Women Writers and Scholars", em 1997 do “Latin American Speaker Simposium”, em Nova York. No ano de 1995, ministrei palestras na Áustria, integrando uma comitiva com escritores brasileiros brancos e negros. A minha recepção lá fora onde sou vista como referência, sem dúvida é melhor do que aqui no Brasil.

$\mathrm{Eu}$ tenho, ainda, duas antologias bilingues de escritoras negras brasileiras, que coorganizei, a primeira foi Enfim nós/Finally us: contemporary black brazilian women writers, 1995, que saiu no Texas, nos Estados Unidos. A segunda de contos Women righting/Mulheres escre-vendo: afro-brazilian women's short fiction, 2005 que saiu em Londres na Inglaterra. Nesse sentido, há diferenças de valorização. Atualmente eu estou tendo mais, vamos dizer, visibilidade em outras mídias, porque, como eu disse, nós fazemos a nossa própria mídia, nós temos no Movimento de Literatura Negra Brasileira, autores, leitores, editores e mercado. Algumas pessoas dizem que a gente é conhecido só na bolha, sem considerar que existem a bolha da literatura do branco, da literatura formal, da literatura que se chama universal, que se chama de letrada, que é uma bolha. Pode ser uma bolha pequena ou grande, mas sem dúvida é uma bolha, basicamente a diferença é essa. Nos meios formais, quando apareço agora, depois de quase quarenta anos de atividade de escrita, com seis livros individuais publicados, várias participações em antologias nos Estados Unidos, na Alemanha e alguma coisa na França também. Causa admiração, aqui no Brasil, a minha trajetória

Gláuks: Revista de Letras e Artes - jul/dez 2020 - v. 20, n. 2 
literária, suscitando comentário: "Mas eu nunca ouvi falar de você". Não é porque você não ouve falar de mim que eu não exista, com uma carreira como escritora e um reconhecimento internacional. A diferença, é sobre o entendimento de visibilidade, se não está aparecendo nos meios televisivos e outras mídias hegemônicas não existimos. Mas, existimos, fazemos literatura, vendemos literatura, estamos sendo discutido lá fora, no exterior, e agora dentro de algumas universidades aqui no Brasil.

\section{Qual a importância da tradução, sobretudo, para o escritor que escreve em português?}

A importância é que a partir das traduções, a minha forma de dizer nos textos fica mais acessível, facilita muito o entendimento da história. Percebi nas minhas viagens que parte do mercado editorial nos Estados Unidos tem muito interesse por essa nossa literatura. Só que existe, uma certa dificuldade, no meu caso, de arrumar pessoas que traduzam para poder oferecer esse trabalho para as editoras que estão interessadas. Se o tradutor, for brasileiro, que entenda as nuances do português brasileiro, a tradução fica mais próxima do contexto do seu poema, conto ou romance. Aproximando as palavras, o seu significado e seu significante dentro do país, do Brasil, para transformá-la num significado e num significante para outra língua, seja ela inglês, francês ou alemão.

Por falar em alemão, eu também fui traduzida em alemão e quem traduziu foi uma brasileira e um alemão, que juntos traduziram meus poemas e contos. Aqui no Brasil, a palavra negro foi ressignificada a partir do MNU e do Movimento de Literatura Negra, para traduzir para o inglês ou alemão, é necessário entender esses contexto e procurar correspondentes em outra língua, é um desafio. Recentemente, eu recebi uma proposta para traduzir para o inglês o meu romance Bará na trilha do vento, o que me surpreendeu, porque, alguns anos recebi a resposta de um tradutor, amigo meu, de que era intraduzível.

Gláuks: Revista de Letras e Artes - jul/dez 2020 - v. 20, n. 2 
4. Quais são os desafios para ser publicado no exterior ou ser traduzido para outra língua?

Primeiro, para ser publicada no exterior, tem que conhecer alguém que possa traduzila. Os meus livros, os meus textos que foram traduzidos partiram do contato, com alguns professores que traduziram gratuitamente. Agora, para eu, aqui no Brasil, propor essa publicação, tem que já estar traduzido e, para isso, tem que pagar, são despesas que não posso arcar. Já tive algumas propostas de publicação, mas tinha que já estar traduzido, aí fíca difícil.

\section{5. "Traduttore, traditore". Como é ler sua obra traduzida para outro idioma? Destacaria algum exemplo?}

Eu sou publicada em francês, inglês e alemão, que eu saiba. Ah! Também tem uma publicação em catalão. Talvez, a pergunta seria mais bem respondida por quem lê minha obra em outro idioma. Eu posso contar como alguns contos foram recebidos, quando estive nos Estados Unidos, em 2009. Foi num encontro, com alunos da faculdade de tradução, com três escritores brasileiros, Ignácio de Loyola Brandão, Almino Afonso, e eu. Uma cidadezinha linda, parecendo uma pintura de presépio. Eu li o meu conto chamado Brincadeiras, cada escritor tinha o seu tradutor, o meu era o Rick Santos. A fala de um dos participantes, depois de ouvir as três obras, em português pelo autor e em inglês pelo tradutor, ele disse que via naquela mesa três Brasis. Que um Brasil não conversava com o outro. Na hora de responder, disse que o Brasil do qual eu estava falando, conhecia os outros dois porque trabalhamos para esses dois Brasis. De contrapartida somos ignorados por esses Brasis que nos desconhece. O outro fato foi quando o professor Luciano Tosta me levou a University of Kansas, por causa do livro organizado por mim Mulheres Negras escrevendo, em inglês saiu como Women righting/Mulheres escre-vendo: afro-brazilian women's short fiction, estavam presentes no evento alunos falantes de inglês. Eu li em português, a tradutora leu em inglês o meu conto chamado Abajur, que retrata a relação sexo-amorosa de um trisal, duas mulheres, uma bissexual, a outra lésbica e um homem, com um final que não explicita, se eles acabam indo 
juntos para cama ou não. Terminado a leitura, um dos alunos se levantou, perguntou em bom inglês, se eles haviam praticado o ato sexual. Eu disse que não sabia, se soubesse estava escrito. Na verdade, eu não sei.

\section{Existe uma "literatura nacional”, presa a um país, a uma região, a uma língua?}

Não, não existe uma literatura presa a um país, a uma região ou uma língua, mas existe uma literatura nacional. A literatura feita num determinado país, pode romper fronteiras, acredito que a literatura ficcional extrapola os limites geográficos e as barreiras linguísticas, porque pode se recorrer a tradução, que auxilia a transpor os empecilhos dos diferentes idiomas. Por exemplo, Maria Carolina de Jesus é traduzida em 25 idiomas, até onde eu sei. É uma literatura que nasce, sai de um determinado lugar geográfico chamado Brasil, duma determinada condição de favela, com falta de acesso aos bens materiais e culturais, com escassez de alimentação. Dentro dessa realidade, a forma como ela escreveu extrapolou as fronteiras do Brasil e os limites da língua portuguesa. A literatura nacional existe a partir do momento que ela é feita por determinados autores, que utilizam os signos linguísticos e os arcabouços simbólicos próprios de um país, mas não é presa a esse país. Extrapola ainda mais, agora, com as redes sociais.

\section{Seu fazer literário busca responder a alguma urgência presente na realidade social brasileira que você gostaria de destacar?}

O meu fazer literário tem um viés na literatura negra brasileira, que se propõem a trazer para o cenário literário, seja na ficção, seja na poesia, o protagonismo do cidadão brasileiro negro, que são $53 \%$ da população, e que os fazeres literários brasileiros majoritariamente não nos fazem protagonistas. Nessas obras predominantemente escrita por autores brancos, estamos, nós os negros, sempre num lugar de escravos, descendentes de escravos e/ou subalternizados em alguma função, sem personalidade e interioridade 
dramática. O meu fazer literário busca exatamente dar interioridade e cognitividade às personagens negras da história, que têm toda uma complexidade de personalidades e de ação, que rompe o binômio: bonzinho-malzinho, bandido-mocinho. Levo em conta que a literatura é a criação do imaginário de um povo, de uma nação, é um lugar de sonho, de questionamentos e muito mais. No meu romance Maréia, 2019, trabalho essa questão da psique, da interioridade, da personagem negra, e da psique complexa da personagem branca. Trabalho com a ideia de que nós, brancos e negros, somos herdeiros do sistema escravocrata, cada qual com seu legado, e que à sociedade branca não passou impune as agruras, carrega uma culpa mal disfarçada em autodefesa para manter-se no poder, já os cidadãos negros se refazem, se recompõe o tempo todo para vencer, existir e ser.

Entrevista transcrita por Laís de Oliveira Moreira. 